\title{
Operation analysis of AC traction motors in terms of electromagnetic torque capability on sustainable railway vehicles
}

\author{
Cornelia A. Bulucea ${ }^{1, a}$, Doru A. Nicola ${ }^{1}$, Marc A. Rosen ${ }^{2}$, Nikos E. Mastorakis ${ }^{3}$ and Carmen A. Bulucea ${ }^{4}$ \\ ${ }^{1}$ University of Craiova, Faculty of Electrical Engineering, Craiova 200440, Romania \\ ${ }^{2}$ University of Ontario Institute of Technology, Faculty of Engineering and Applied Science, Oshawa, ON, L1H 7K4, Canada \\ ${ }^{3}$ Military Institutions of University Education (ASEI), Hellenic Naval Academy, Piraeus 18539, Greece \\ ${ }^{4}$ University of Medicine and Pharmacy of Craiova, Faculty of Medicine, Craiova 200349, Romania
}

\begin{abstract}
Sustainable operation of electric railway systems represents a significant purpose nowadays in the development of high power and high speed locomotives and trains. At present, high speed electric vehicles mostly work with three-phase induction motors or three-phase synchronous motors as traction motors. The two electric machine types have different efficiencies at different operation points, and experience differences with respect to safety, speed and power, energy use and exergy efficiency. An important issue that correlates these aspects is the electromagnetic torque developed by an electric traction motor. In order to provide an overview of the technical performance of the operation of sustainable railway systems, a detailed analysis is carried out of the electromagnetic torque capability of AC electric motors utilized as traction motors in modern locomotives of high power and/or high speed. The results of this work may help in enhancing the main criteria for optimising the safe and sustainable operation of electric railway traction systems.
\end{abstract}

\section{Introduction}

The final decades of the $20^{\text {th }}$ century and the first decade of the $21^{\text {st }}$ century were marked by a significant rise in the speed of electric railway vehicles due to progress in power electronics for electric locomotive technology [17]. Consequently, nowadays we are encountering a rethinking and redrawing of the architecture of electric railway vehicles, regardless of the type of the electric contact line (in DC or in AC). Under the vision of sustainable development and industrial ecology, the key points of operation of electric railway vehicles nowadays are related to the high electromagnetic torque developed by traction motors, energy savings and environmental impact mitigation, particularly through high exergy efficiency [1-2,4-6]. Moreover, the variable voltage/current variable frequency $(\mathrm{VV} / \mathrm{CVF})$ power conversion technology facilitates the use of on-board AC drives which ensure regenerative braking and thus make possible efficient management of energy supply of high speed trains [1-8]. But note that these advantages are met under the condition of using in traction drives the $\mathrm{AC}$ electric motors, namely of induction type or synchronous type, regardless of the contact line type.

The rivalry between the two three-phase AC traction electric motors, namely the induction motor and synchronous motor persists, each competing to be the safest, fastest and cheapest [4-7]. The two electric machine types have different efficiencies at different

\footnotetext{
a Corresponding author: abulucea@em.ucv.ro
}

operation points in terms of electromagnetic torque [1-8]. An accurate insight into these two types of electric traction motors (three-phase induction motors and threephase synchronous motors) is presented subsequently.

The three-phase induction motor with squirrel-cage rotor meets the criteria for an ideal traction motor, since it is robust and reliable, having fewer components than the DC traction motor. Moreover, for this type of electric motor the energy transfer between the stator and the rotor is performed without an electric contact, but instead just through the electromagnetic field, so that there are no limitations with respect to power, speed or voltage. Note that switching to the braking regime, or sense reversal, are achieved through the control logic of the power converters, without electromechanical contactors [1,4-7].

Further, a comparison of the traction motor with collector shows that the three-phase induction motor with a cage rotor presents an advantage in that, for the same useful power, the size and weight are lower.

The traction induction motors used on the locomotives and high speed/power trains are robust, with rated powers up to $1.5 \mathrm{MW}$. As a traction motor the induction motor must satisfy several criteria [1-2,4-7]:

- $\quad$ high torque developed at low speeds, even during start-up, and

- operation over a large range of the supply frequency, from roughly $0.4-1 \mathrm{~Hz}$ to $140-180 \mathrm{~Hz}$, both as a motor and as a brake (generator). 
The technology becomes significantly complicated in the range of low frequencies (under the rated frequency) because the motor is submitted to magnetic saturation at relatively small variations of supply voltage. For this reason, in the under-rated frequency range, the voltage will vary simultaneously with the supply frequency, in order to enable through the control system both the appropriate level of magnetic stresses and the required magnitude of the electromagnetic torque [1, 4-7].

But developments should be made in the range of over-rated frequencies for which, due to reasons of motor windings insulation and voltage stresses of power electronics, the supply voltage must be maintained constant at the level of rated voltage $\mathrm{U}_{\mathrm{N}}$. Consequently, when powered at the rated voltage $\mathrm{U}_{\mathrm{N}}$ and over-rated frequencies, the induction motor operates with weakened flux, which leads to the torque overloading capability $\lambda_{\mathrm{M}}$ becoming increasingly lower and the rotor pulsation $\omega_{\mathrm{r}}$ becoming increasingly higher. Besides, for the operation in the range of over-rated frequencies, the reaching of critical rotor pulsation $\omega_{\mathrm{rk}}$ limits the higher value of the stator frequency to below the maximum $f_{\text {smax }}[1-2,4-7]$.

The synchronous motor utilized as traction motor must develop significant high electromagnetic torques at variable speeds, namely from the starting to the maximum speed. Consequently it is compulsory the traction synchronous motor to be powered from a static converter with variable frequency so that the rotor, which controls the static converter to maintain the synchronization with the rotating magnetic field at any value of stator frequency $[1,8-9]$.

Following this idea means that the current converters with natural commutation which power the selfcontrolled three-phase traction synchronous motors are simple, being composed by six thyristorised branches connected as a three-phase bridge. Note that some problems concerning the natural commutation realisation appear at very low speeds, when the magnitude of the counter electromotive force (c.e.m.f) is small (insufficient to ensure the commutation). In such situations, from the starting regime up to roughly $5-10 \%$ of the maximum speed $\mathrm{v}_{\max }$, assisted commutation is necessary [1, 6, 8-9].

The self-controlled synchronous motor becomes competitive as a traction motor solely at high powers, which is exactly in the application field of electric railway locomotives/trains. Specifically, three-phase traction synchronous motors with unit powers up to $1300 \mathrm{~kW}$ (in continuous operation regime) with forced ventilation are manufactured, of axial type (being provided with axial channels in the stator ferromagnetic core).

In this study, we perform a detailed analysis of the electromagnetic torque developed by the three-phase induction motor and the three-phase synchronous motor, the most generally used traction AC electric motors in present-day railway systems. We focus here on these two types of AC motors, which are widely used as traction motors on electric railway transportation systems, with particular reference to electromagnetic torque analysis, since certain traits of the developed electromagnetic torque are strongly related to the safety, speed, exergy efficiency and energy savings of high power and speed locomotives and trains. The aim of this study is to enhance understanding of these motors and their use in railway systems. Consequently, we present in the paper some less known theoretical aspects of the operation at variable frequency of $\mathrm{AC}$ traction motors.

\section{Analysis of electromagnetic torque developed by traction induction motor}

To address meaningfully many of the problems facing railway vehicles, conditions for the performance of sustainable transportation systems must be formulated [2$3,10]$. Costs should reflect value, which is doubtless associated with sustainability aspects [10-12]. The sustainability of traction operation of the electric induction motor is related its exergy efficiency.

In physics and engineering, work is a specific form of action, and exergy is defined based on work, i.e. ordered motion, or ability to perform work [2,10-13]. While energy is a measure of quantity only, exergy is a measure of quantity and quality or usefulness. Since exergy is a measure of the potential of a system to do work, the electromagnetic torque $\mathrm{M}$ developed by an induction motor can be interpreted as the driving force of useful work, i.e. the electric motor output exergy $[2-3,10,13]$.

In line with this idea, through the modeling of the electromagnetic torque developed by induction motor, this study supports the findings that electric traction drive systems using induction motors fed by VVVF inverters enhance the sustainable operation of railway trains.

In order to assess the electromagnetic torque developed by the traction induction motor, the vehicle regulation speed is determined by examining the VVVF inverter and electric machine as an assembly [1-3]. We have pointed out in previous studies $[1-3,10,13]$ that a traction electric vehicle might be analyzed as an ecosystem, and the dynamic regimes in electric train operation, e.g. starting or braking processes, can be viewed as representing the industrial ecosystem movement among points of equilibrium. Since the traction motor speed regulation is based on stator voltage and frequency variation, in order to achieve high energy and exergy efficiencies, the first requirement of the train control system concerns passing of the motor operation equilibrium point from one mechanical characteristic to another $[1-3,13]$.

If we note by $s=\frac{n_{s}-n}{n_{s}}=\frac{\omega_{r}}{\omega_{s}}=\frac{f_{r}}{f_{s}}$ the slip of rotor (having the speed $\mathrm{n}$ ) in the rotating magnetic field (which has the synchronism speed $\left.n_{s}=60 \cdot f_{s} / p\right)$, then the electromagnetic torque $\mathrm{M}$ developed by the traction induction motor at any current value of the stator frequency $\mathrm{f}_{\mathrm{s}}$ and rotor slip s (respectively, rotor pulsation $\omega_{\mathrm{r}}=\mathrm{s} \cdot \omega_{\mathrm{s}}$ ) is specified by $M=\frac{3 p}{\omega_{s}} \cdot \frac{R_{r}{ }^{\prime}}{s} \cdot I_{r}{ }^{2}=3 p \cdot \frac{R_{r}{ }^{\prime}}{\omega_{r}} \cdot I_{r}{ }^{2}$.

Neglecting the stator resistance $\left(\mathrm{R}_{\mathrm{s}} \approx 0\right)$, the evaluation relation of the electromagnetic torque $\mathrm{M}$ becomes: 


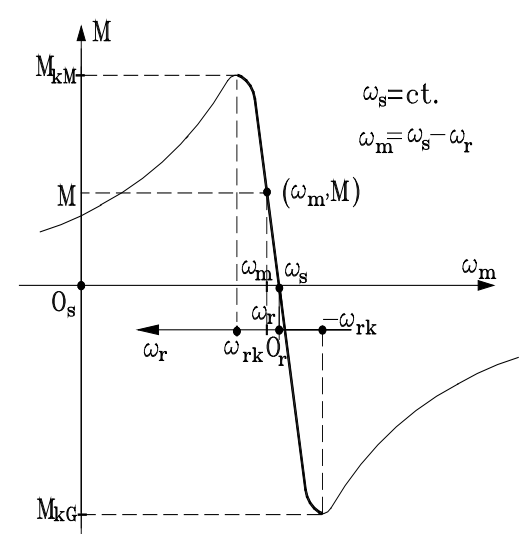

Figure 1. Mechanical characteristic $\mathrm{M}=\mathrm{f}\left(\omega_{\mathrm{m}}\right)$ at $\omega_{\mathrm{s}}=\mathrm{ct}$.

$$
M=M\left(\omega_{s}, \omega_{r}\right)=3 p \cdot \frac{1-\sigma}{\sigma \cdot L_{s}} \cdot \frac{\left(\frac{U_{s}}{\omega_{s}}\right)^{2}}{\frac{R_{r}^{\prime}}{\omega_{r} \cdot \sigma \cdot L_{r}^{\prime}}+\frac{\omega_{r} \cdot \sigma \cdot L_{r}^{\prime}}{R_{r}^{\prime}}}
$$

With the notation $\omega_{m}=p \cdot \Omega_{m}=p \frac{2 \pi \cdot n}{60}$, the torque characteristic of the induction motor, meaning the curve $\mathrm{M}=\mathrm{f}\left(\omega_{\mathrm{m}}\right)$ for any constant pulsation/frequency $\omega_{\mathrm{s}}=2 \pi \mathrm{f}_{\mathrm{s}}$ $=$ ct. and $\omega_{\mathrm{m}}=\omega_{\mathrm{s}}-\omega_{\mathrm{r}}$ is graphically illustrated in Figure 1 . The specific points of the mechanical characteristic in Figure 1 have coordinates (for any constant value of the stator frequency $\mathrm{f}_{\mathrm{s}}$ ) given by:

- mechanical pulsation $\omega_{\mathrm{m}}$ corresponding to the synchronism point $\left(\right.$ when $\left.\omega_{\mathrm{r}}=0\right)$ :

$$
\omega_{m}=\omega_{s}=2 \pi \cdot \mathrm{f}_{\mathrm{s}}=2 \pi \frac{p \cdot n_{s}}{60}
$$

- critical rotor pulsations $\omega_{\mathrm{rk}}$ (extreme points' abscissa of the graph in Figure 1):

$$
\omega_{\mathrm{rk}}=\omega_{\mathrm{rk} \psi \mathrm{s}}= \pm \frac{\mathrm{R}_{\mathrm{r}}^{\prime}}{\sigma \cdot \mathrm{L}_{\mathrm{r}}^{\prime}}
$$

- extreme values (as motor $\mathrm{M}_{\mathrm{kM}}$ and respectively as generator $\mathrm{M}_{\mathrm{kG}}$, of the torque curve), given by:

$$
M_{k}=M_{k \psi_{s}}= \pm \frac{3 p}{2} \cdot \frac{1-\sigma}{\sigma \cdot L_{s}} \cdot\left(\frac{U_{s}}{\omega_{s}}\right)
$$

Note in the above relation that the sign "+" refers to the motor regime (with index $M$ in Figure 1) while the sign "-" refers to the generator regime (with index G in Figure 1).

\subsection{Limits of variation of stator frequency}

For the supply with variable frequency voltages it is important to assess the limit values of stator minimum frequency $f_{\text {smin }}$ and maximum frequency $f_{\text {smax }}$ (as in Figure 2, in the bottom part) among which the stable operation of the traction induction machine is possible.

\subsubsection{Minimum frequency}

The minimum frequency (for operation with constant stator flux, see Figure 2) is assessed taking into consideration that in a steady-state regime, at any value of stator frequency $\mathrm{f}_{\mathrm{s}}$, among rotor pulsation $\omega_{\mathrm{r}}$, stator pulsation $\omega_{\mathrm{s}}=2 \pi \cdot \mathrm{f}_{\mathrm{s}}$ and mechanical pulsation $\omega_{\mathrm{m}}=\mathrm{p} \cdot \Omega_{\mathrm{m}}$ $=\mathrm{p} \cdot 2 \pi \cdot \mathrm{n} / 60$, the "Frequency Theorem" relation is valid:

$$
\omega_{s}=\omega_{m}+\omega_{r}
$$

or

$$
2 \pi \cdot f_{s}=p \cdot \frac{2 \pi \cdot n}{60}+\omega_{r} \Rightarrow n=\frac{60}{p} \cdot\left(f_{s}-\frac{1}{2 \pi} \cdot \omega_{r}\right)
$$

For any stator frequency $f_{s}<f_{N}$, the rotor speed $n_{k}$ corresponding to maximum electromagnetic $\mathrm{M}$ (meaning the abscissa of point $\mathrm{K}_{\mathrm{M}}$ in Figure 2) is established with the relation:

$$
n_{k}=\frac{60}{p} \cdot\left(f_{s}-\frac{1}{2 \pi} \cdot \omega_{r k \psi_{s}}\right) ; \quad n_{k} \geq 0
$$

The minimum stator frequency $\mathrm{f}_{\mathrm{smin}}$ (that still will ensure the above operation conditions) corresponds to the limit situation when $\mathrm{n}_{\mathrm{k}}=0$. That means that the minimum stator frequency will be given by the relation:

$$
f_{\text {smin }}=\frac{1}{2 \pi} \cdot \omega_{r k \psi_{s}}=\frac{1}{2 \pi} \cdot \frac{R_{r}^{\prime}}{\sigma \cdot L_{r}^{\prime}}
$$

Note that $f_{\text {smin }}$ must be ensured by the supply source (VVVF) and depends solely on the parameters $\mathrm{R}_{\mathrm{r}}^{\prime}, \mathrm{L}_{\mathrm{r}}^{\prime}$ and $\sigma$ of the traction induction machine.

In Figure 2, the smooth starting manner (without shocks) is highlighted, through a progressive increase of the stator flux $\psi_{\mathrm{s}}$ (from 0 up to $\psi_{\mathrm{sN}}$ ) at the minimum value $\mathrm{f}_{\text {smin }}=$ ct. (of the supply stator frequency), followed by an increase of the stator frequency $\mathrm{f}_{\mathrm{s}}$ (at the constant stator flux a $\psi_{\mathrm{s}}=\psi_{\mathrm{sN}}=$ ct.) simultaneously with the increase of rotor speed.

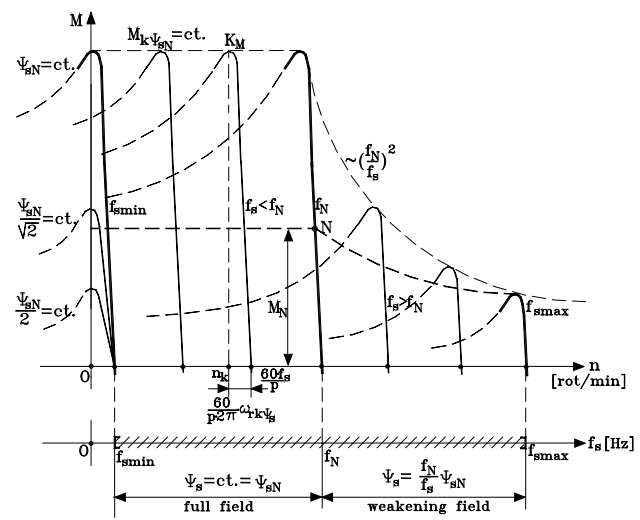

Figure 2. Overview of traction induction motor characteristics for operation at variable stator frequency $f_{s}$

\subsubsection{Maximum frequency}

The maximum stator frequency $f_{s \text { max }}$ (higher than $\mathrm{f}_{\mathrm{N}}$ ) will be established by the condition of development (still) of an electromagnetic power $\mathrm{P}_{\mathrm{M}}$ of magnitude equal to that of the motor rated operation.

Note that because of the voltage restriction on both supply inverter and induction machine winding insulation considerations, the stator voltage is limited and maintained at a constant magnitude $\mathrm{U}_{\mathrm{s}}=\mathrm{U}_{\mathrm{N}}$ when $\mathrm{f}_{\mathrm{s}}>\mathrm{f}_{\mathrm{N}}$ and the induction machine operates in weakened flux conditions [17]. Since the stator flux and stator pulsation exhibit an 
inverse proportionality relation, the machine torque capability is strongly affected (see Figure 2). This is the reason for the limited increase of stator frequency.

Simultaneously, due to the decrease of flux $\psi_{\mathrm{s}}$ on the basis of the law " $1 / \omega_{\mathrm{s}}$ ":

$$
\psi_{s}=\psi_{s N} \cdot \frac{\omega_{N}}{\omega_{s}} \approx \frac{U_{N}}{\omega_{s}}
$$

a reduction of the maximum electromagnetic torque occurs, and its equation (4) at over-rated frequencies $f_{s}>$ $\mathrm{f}_{\mathrm{N}}$ becomes:

$$
M_{k \psi_{s}}=\frac{3 p}{2} \cdot \frac{1-\sigma}{\sigma \cdot L_{s}} \cdot\left[\psi_{s N} \cdot \frac{\omega_{N}}{\omega_{s}}\right]^{2}=M_{k \psi_{s N}} \cdot\left(\frac{\omega_{N}}{\omega_{s}}\right)^{2}
$$

In this context, the maximum value of the stator frequency $f_{\text {smax }}$ is established from the electromagnetic power invariance condition $\mathrm{P}_{\mathrm{M}}=\mathrm{M} \cdot \Omega_{\mathrm{s}}=\mathrm{M} \cdot \omega_{\mathrm{s}} / \mathrm{p}$ (transferred by air-gap) at different over-rated values of stator frequency $f_{s}$.

In order to maintain a constant electromagnetic power $\mathrm{P}_{\mathrm{M}}=\mathrm{M} \cdot \Omega_{\mathrm{s}}=\mathrm{M} \cdot \omega_{\mathrm{s}} / \mathrm{p}$ (at nominal level $\mathrm{P}_{\mathrm{MN}}=$ ct.) even for the maximum stator frequency $f_{\text {smax }}$, the following relation can be written:

$$
M_{N} \cdot \frac{\omega_{N}}{p}=M_{f_{\text {smax }}} \cdot \frac{\omega_{\text {smax }}}{p}
$$

If at the maximum frequency $f_{\text {smax }}$ the condition $M_{f_{\text {smax }}}=M_{k \psi_{s}}$ is imposed, the following results:

$M_{N} \cdot \frac{\omega_{N}}{p}=M_{k \psi_{s N}} \cdot\left(\frac{\omega_{N}}{\omega_{s \max }}\right)^{2} \cdot \frac{\omega_{s \max }}{p} \Rightarrow \omega_{s \operatorname{smax}}=\frac{M_{k \psi_{s N}}}{M_{N}} \cdot \omega_{N}$

or taking into account the definition of the torque overload capacity $\lambda_{\mathrm{M}}$ we obtain:

$$
\lambda_{M}=\frac{M_{k \psi_{s N}}}{M_{N}} \Rightarrow f_{\text {smax }}=\lambda_{M} \cdot f_{N}
$$

Consequently, the increase of the maximum frequency $\mathrm{f}_{\text {smax }}$ can be achieved through the design and further construction of induction machines with increased torque overload capacity $\lambda_{\mathrm{M}}$. For traction induction machines, $\lambda_{\mathrm{M}}$ can take on values of 2.5 to 3.0 .

\subsection{Torque capability and comparison at constant flux operation}

Note that, at any frequencies, in the permanent harmonic regime, among the fluxes $\underline{\Psi}_{\mathrm{s}}, \underline{\Psi}_{\mathrm{u}}, \underline{\Psi}_{\mathrm{r}}^{\prime}$ and the currents $\underline{I}_{\mathrm{s}}$, $\underline{I I}_{r}^{\prime}$ of any unsaturated induction machine with electric and magnetic symmetry, the following relations apply [1, 13]:

$$
\begin{gathered}
\underline{\psi}_{s}=L_{s \sigma} \cdot \underline{I}_{s}+\underline{\psi}_{u} \\
\underline{\psi}_{s}=\sigma \cdot L_{s} \cdot \underline{I}_{s}+\frac{L_{u}}{L_{r^{\prime}}} \cdot \underline{\psi}_{r}{ }_{r} \\
\underline{\psi}_{r}{ }_{r}=\underline{\psi}_{u}+{\underline{L^{\prime}}}_{r \sigma} \cdot \underline{I}_{r}^{\prime} \\
0=R_{r}^{\prime}+j \omega_{r} \cdot \underline{\psi}_{r}{ }_{r}
\end{gathered}
$$

Accordingly, a phasor diagram is shown in Fig. 3 of the fluxes and currents for the induction machine operating in the motor regime. In the complex reference system, with real axis $(+1)$ along the direction of phasor
$\underline{\Psi}_{r}^{\prime}$ (with $\underline{\Psi}_{r}^{\prime}=\Psi_{r}^{\prime}+j \cdot 0 ; \underline{I}_{s}=I_{s x}+j \cdot I_{\text {sy }}$ and $\left.\underline{I}_{r}^{\prime}=0-j \cdot I_{r}^{\prime}\right)$, from the geometry of the rectangular triangles $\mathrm{OAA}^{\prime}$ and $\mathrm{OBB}^{\prime}$ (see Fig. 3) one can write:

$$
\begin{aligned}
& \psi_{s}^{2}=\left[\frac{L_{u}}{L_{r^{\prime}}} \cdot \psi_{r}^{\prime}+\sigma \cdot L_{s} \cdot I_{s x}\right]^{2}+\left(\sigma \cdot L_{s} \cdot I_{s y}\right)^{2}
\end{aligned}
$$

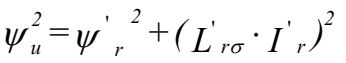

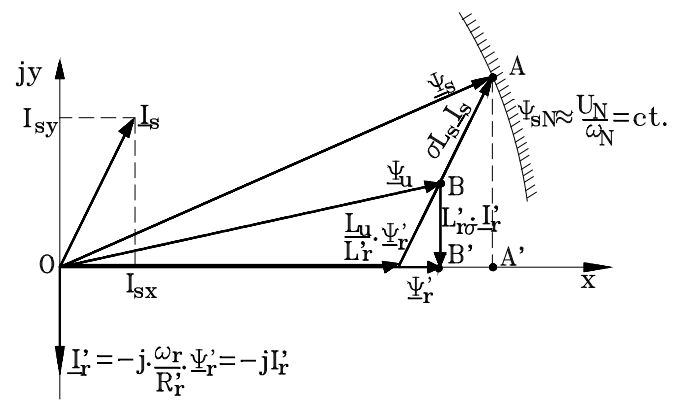

Figure 3. Phasor representation of induction motor fluxes and currents at $\omega_{\mathrm{r}}>0$

Furthermore, taking into consideration the components $I_{\mathrm{sx}}$ and $I_{\mathrm{sy}}$, as well as the rotor current $I_{r}^{\prime}$ in accordance with the following relations:

$$
I_{s x}=\frac{\psi_{r}^{\prime}}{L_{u}} ; I_{s y}=\frac{\psi^{\prime}{ }_{r}}{L_{u}} \cdot \frac{L_{r}^{\prime}{ }_{r}}{R^{\prime}{ }_{r}} \cdot \omega_{r} ; I^{\prime}{ }_{r}=\frac{\omega_{r}}{R^{\prime}{ }_{r}} \cdot \psi^{\prime}{ }_{r}
$$

and $_{2}$ after mathematical calculations, the expressions for the fluxes $\Psi_{\mathrm{u}}$ and $\Psi^{\prime}{ }_{\mathrm{r}}$ can be determined:

$$
\begin{gathered}
\psi_{u}\left(\omega_{r}\right)=\psi_{s} \cdot \frac{L_{u}}{L_{s}} \cdot \sqrt{\frac{1+\left(\frac{L_{r \sigma}^{\prime}}{R^{\prime}{ }_{r}} \cdot \omega_{r}\right)^{2}}{1+\left(\frac{\sigma \cdot L_{r}^{\prime}}{R_{r}{ }_{r}} \cdot \omega_{r}\right)^{2}}} \\
\psi_{r}^{\prime}\left(\omega_{r}\right)=\psi_{s} \cdot \frac{L_{u}}{L_{s}} \cdot \frac{1}{\sqrt{1+\left(\frac{\sigma \cdot L_{r}^{\prime}}{R_{r}{ }_{r}} \cdot \omega_{r}\right)^{2}}}
\end{gathered}
$$

Note that the fluxes $\Psi_{\mathrm{u}}$ and $\Psi_{\mathrm{r}}^{\prime}$ depend on $\Psi_{\mathrm{s}}$, as well on machine parameters and on $\omega_{\mathrm{r}}$. But any induction machine designed to be supplied with phase voltage $U_{N}$ at stator frequency $f_{N}\left(\omega_{N}=2 \pi \cdot f_{N}\right)$ will have the stator flux $\Psi_{\mathrm{s}}$ approximately constant, with magnitude $\Psi_{\mathrm{sN}}$, where:

$$
\psi_{s N} \approx \frac{U_{N}}{\omega_{N}}=c t \text {. }
$$

Hence, for operation with constant stator flux $\left(\Psi_{\mathrm{s}}=\Psi_{\mathrm{sN}}=\right.$ ct.), the reference levels of the fluxes $\Psi_{\mathrm{u}}=$ ct. and $\Psi_{\mathrm{r}}^{\prime}=$ ct., respectively should set to values such that, over the entire variation range of rotor pulsation $\omega_{\mathrm{r}}$, the stator flux $\Psi_{\mathrm{s}}$ does not exceed the established limit value. Therefore, in Fig. 4 there are shown the dependence $\Psi_{\mathrm{s}}=\Psi_{\mathrm{sN}}=$ ct. in accordance with $(18)$, and $\Psi_{\mathrm{u}}=\mathrm{f}_{1}\left(\omega_{\mathrm{r}}\right)$ and $\Psi_{\mathrm{r}}^{\prime}=\mathrm{f}_{2}\left(\omega_{\mathrm{r}}\right)$ according to (17) for the maximum variation range of $\omega_{\mathrm{r}}$ $\left(\left|\omega_{\mathrm{r}}\right| \leq \mathrm{R}_{\mathrm{r}}^{\prime} / \mathrm{L}_{\mathrm{r} \sigma}^{\prime}\right.$ when the induction machine has stable operation at $\Psi_{\mathrm{u}}=$ ct.) 


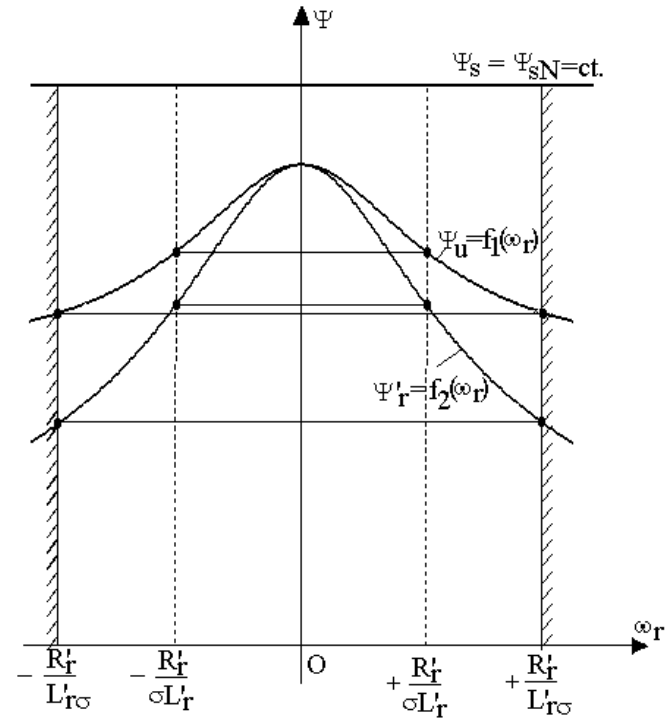

Figure 4. Dependence of induction machine fluxes $\Psi_{\mathrm{s}}, \Psi_{\mathrm{u}}$ and $\Psi_{\mathrm{r}}^{\prime}$ on $\omega_{\mathrm{r}}$

Based on the curves of Fig. 4 and the above relations, the constant flux levels are determined:

$$
\begin{gathered}
\psi_{s}=\psi_{s N}=c t . \\
\psi_{u}=f_{1}\left( \pm \frac{R_{r}^{\prime}}{L_{r \sigma}^{\prime}}\right)=\psi_{s} \cdot \frac{L_{u}}{L_{s}} \cdot \frac{\sqrt{2}}{\sqrt{1+\left(\frac{\sigma L_{r}^{\prime}}{L_{r \sigma}^{\prime}}\right)^{2}}}=c t . \\
\psi_{r}^{\prime}=f_{2}\left( \pm \frac{R_{r}^{\prime}}{L_{r \sigma}^{\prime}}\right)=\psi_{s} \cdot \frac{L_{u}}{L_{s}} \cdot \frac{1}{\sqrt{1+\left(\frac{\sigma_{L_{r}^{\prime}}^{\prime}}{L_{r \sigma}^{\prime}}\right)^{2}}}=c t . \quad\left(\psi_{r}^{\prime}=\frac{\psi_{u}}{\sqrt{2}}\right)
\end{gathered}
$$

For these constant values of fluxes $\Psi_{\mathrm{s}}, \Psi_{\mathrm{u}}$ and $\Psi_{\mathrm{r}}^{\prime}$, an exergetic analysis imposes the electromagnetic torque characteristics $\mathrm{M}=\mathrm{f}\left(\omega_{\mathrm{r}}\right)$, and stator current characteristics $I_{\mathrm{s}}=\mathrm{f}\left(\omega_{\mathrm{r}}\right)$ are compared for the stable operation intervals.

\subsubsection{Electromagnetic torques comparison at $\Psi_{s}=$ ct., $\Psi_{u}=c t$. and $\Psi_{r}^{\prime}=c t$.}

For the three subsequent cases, the electromagnetic torque $\mathrm{M}$ has the following expressions:

a) When stator flux is constant $\Psi_{\mathrm{s}}=$ ct.:

$$
\begin{aligned}
& M=\frac{2 \cdot M_{k \psi_{s}}}{\frac{\sigma \cdot L_{r}^{\prime} \cdot \omega_{r}}{R_{r^{\prime}}}+\frac{R_{r^{\prime}}}{\sigma \cdot L_{r}^{\prime} \cdot \omega_{r}}} \\
& M_{k \psi_{s}}=\frac{3 p}{2} \cdot \frac{1-\sigma}{\sigma \cdot L_{s}} \cdot \psi_{s}^{2}
\end{aligned}
$$

b) When useful flux is constant $\Psi_{\mathrm{u}}=$ ct.:

$$
\begin{gathered}
M=\frac{2 \cdot M_{k \psi_{u}}}{\frac{L_{r \sigma}^{\prime} \cdot \omega_{r}}{R^{\prime}{ }_{r}}+\frac{R^{\prime}{ }_{r}}{L_{r \sigma}^{\prime} \cdot \omega_{r}}} \\
M_{k \psi_{u}}=\frac{3 p}{2} \cdot \frac{1}{L_{r \sigma}^{\prime}} \cdot \psi_{u}^{2}
\end{gathered}
$$

c) When rotor flux is constant $\Psi_{\mathrm{r}}^{\prime}=$ ct.:

$$
M=3 p \cdot \frac{\omega_{r}}{R^{\prime}{ }_{r}} \cdot \psi^{\prime}{ }_{r}{ }^{2}
$$

Moreover, according to the constant flux levels (19), between the maximum torques $\mathrm{M}_{\mathrm{k} \Psi \mathrm{s}}$ and $\mathrm{M}_{\mathrm{k} \Psi \mathrm{u}}$ the following recurrence relationship can be demonstrated:

$$
\frac{M_{k \psi_{s}}}{M_{k \psi_{u}}}=\frac{1}{2} \cdot\left(\frac{\sigma \cdot L_{r}^{\prime}}{L_{r \sigma}^{\prime}}+\frac{L_{r \sigma}^{\prime}}{\sigma \cdot L_{r}^{\prime}}\right)
$$

Also, since the electromagnetic torque is interpreted as output exergy, based on the observation $\Psi_{\mathrm{r}}{ }_{\mathrm{r}}=\Psi_{\mathrm{u}} / \sqrt{ } 2=$ ct., at $\Psi_{r}^{\prime}=$ ct. a relationship for the electromagnetic torque $\mathrm{M}$ can be useful within the exergetic analysis:

$$
M=M_{k \psi_{u}} \cdot \frac{L_{r \sigma}^{\prime}}{R_{r}^{\prime}{ }_{r}} \cdot \omega_{r}
$$

Graphically, curves of the induction machine electromagnetic torque $\mathrm{M} / \mathrm{M}_{\mathrm{k} \Psi_{\mathrm{s}}}=\mathrm{f}\left(\omega_{\mathrm{r}}\right)$ at $\Psi_{\mathrm{s}}=$ ct., $\Psi_{\mathrm{u}}=$ ct., and $\Psi_{\mathrm{r}}^{\prime}=$ ct., respectively, are presented in Fig. 5.

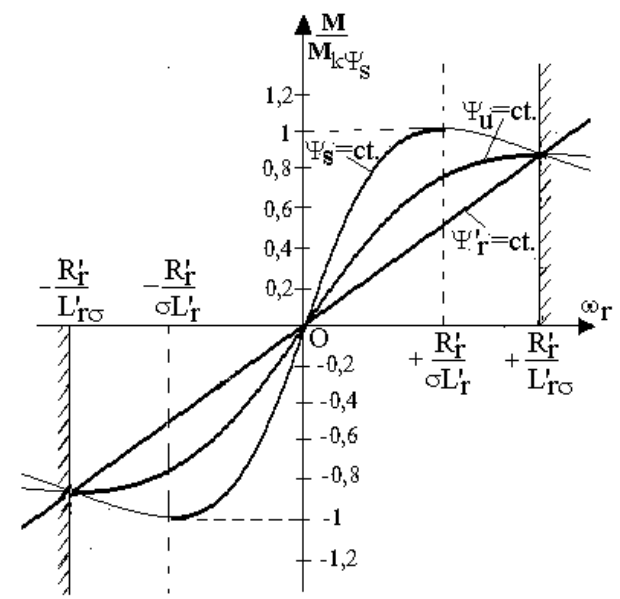

Figure 5. Curves of $\mathrm{M} / \mathrm{M}_{\mathrm{k} \Psi \mathrm{s}}=\mathrm{f}\left(\omega_{\mathrm{r}}\right)$ at constant flux

\subsubsection{Stator currents comparison at $\Psi_{s}=c t$., $\Psi_{u}=c t$ and $\Psi_{r}^{\prime}=c t$.}

According to relationship (19) for constant flux levels, the stator current $I_{\mathrm{s}}$ expressions become as follows:

a) When stator flux is constant $\Psi_{\mathrm{s}}=$ ct.:

$$
I_{s}=\frac{\psi_{s}}{L_{s}} \cdot \sqrt{\frac{1+\left(\frac{L_{r}^{\prime}}{R^{\prime}{ }_{r}} \cdot \omega_{r}\right)^{2}}{1+\left(\frac{\sigma \cdot L_{r}^{\prime}}{R^{\prime}{ }_{r}} \cdot \omega_{r}\right)^{2}}}
$$

b) When useful flux is constant $\Psi_{\mathrm{u}}=$ ct.:

$$
I_{s}=\frac{\psi_{s}}{L_{s}} \cdot \frac{\sqrt{2}}{\sqrt{1+\left(\frac{\sigma \cdot L_{r}^{\prime}}{L_{r \sigma}^{\prime}}\right)^{2}}} \cdot \sqrt{\frac{1+\left(\frac{L_{r}^{\prime}}{R_{r}^{\prime}} \cdot \omega_{r}\right)^{2}}{1+\left(\frac{L_{r \sigma}^{\prime}}{R_{r}^{\prime}} \cdot \omega_{r}\right)^{2}}}
$$

c) When rotor flux is constant $\Psi_{\mathrm{r}}^{\prime}=$ ct.:

$$
I_{s}=\frac{\psi_{s}}{L_{s}} \cdot \frac{1}{\sqrt{1+\left(\frac{\sigma \cdot L_{r}^{\prime}}{L_{r \sigma}^{\prime}}\right)^{2}}} \cdot \sqrt{1+\left(\frac{L_{r}^{\prime}}{R_{r}^{\prime}} \cdot \omega_{r}\right)^{2}}
$$

Graphically, in Fig. 6 there are depicted the characteristics of stator current $\mathrm{I}_{\mathrm{s}}$ at $\Psi_{\mathrm{s}}=$ ct., $\Psi_{\mathrm{u}}=$ ct., and 
$\Psi_{\mathrm{r}}^{\prime}=$ ct., respectively.

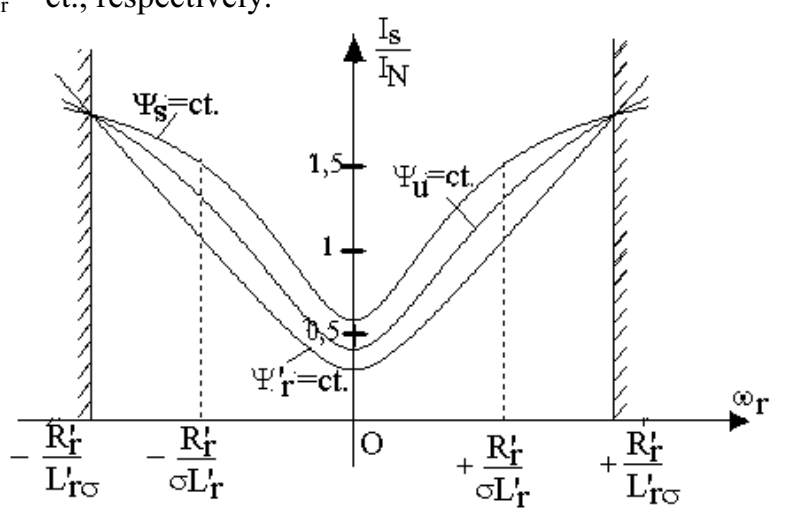

Figure 6. Characteristics of $I_{s} / I_{N}=f\left(\omega_{r}\right)$ at constant flux

\subsubsection{Discussion of torques}

The greatest magnitudes of electromagnetic torque are obtained when operating at $\Psi_{\mathrm{s}}=\mathrm{ct}$. Moreover, with the usual approximations $\sigma \cdot L_{r}^{\prime}=L_{s \sigma}+L_{r \sigma}^{\prime}$ and $\mathrm{L}_{\mathrm{r} \sigma} \mathrm{L}_{\mathrm{s} \sigma}$, the maximum torque relationship is obtained in the form:

$$
M_{k \psi_{u}} \approx \frac{4}{5} \cdot M_{k \psi_{s}}
$$

This emphasizes that the maximum electromagnetic torque in operating at $\Psi_{\mathrm{u}}=$ ct. is approximately with $20 \%$ smaller than the maximum torque in operating at $\Psi_{\mathrm{s}}=$ ct. The ratio of the critical rotor pulsations $\omega_{r k \Psi_{s}}$ and $\omega_{r k} \Psi_{u}$ is:

$$
\frac{\omega_{r k \psi_{s}}}{\omega_{r k \psi_{u}}}=\frac{L^{\prime}{ }_{r \sigma}}{\sigma \cdot L_{r}^{\prime}} \approx \frac{1}{2}
$$

This means that an "inferior" maximum torque $\mathrm{M}_{\mathrm{k} \Psi \mathrm{u}}$ is developed at the rotor pulsation with a double value that of the rotor pulsation corresponding to $\mathrm{M}_{\mathrm{k} \Psi_{\mathrm{s}}}\left(\omega_{\mathrm{rk} \Psi \mathrm{u}}=\right.$ $\left.2 \cdot \omega_{\mathrm{rk}} \Psi_{\mathrm{s}}\right)$.

Moreover, at the imposed electromagnetic torque, the smallest value of rotor pulsation is obtained in operation with $\Psi_{\mathrm{s}}=$ ct.

From Fig. 6 similar observations are drawn with regard to the stator currents. Actually, the smallest values of stator currents $I_{S}$ are obtained for operation with $\Psi^{\prime}{ }_{r}=$ ct.

The analysis of induction machine operation with constant flux highlights that only at $\Psi_{\mathrm{r}}^{\prime}=$ ct. do the mechanical characteristics not have extremum points; they are straight lines. These linear characteristics are preferable for applications which demand high sustainability dynamics in induction machine operation.

\section{Analysis of electromagnetic torque developed by traction synchronous motor}

Like a traction motor, the three-phase synchronous motor with salient poles is powered from a three-phase source, ideally with sinusoidal currents. In this case the current phasor I (through the reference stator winding) is specified by its magnitude $|\underline{I}|=I$ and the initial phase $\psi$ to the axis $\mathrm{q}$ of the rotor, as in Figure 7. This means that implicitly the components $I_{d}$ and $I_{q}$ are specified of the stator current I $[1,9,14-15]$.
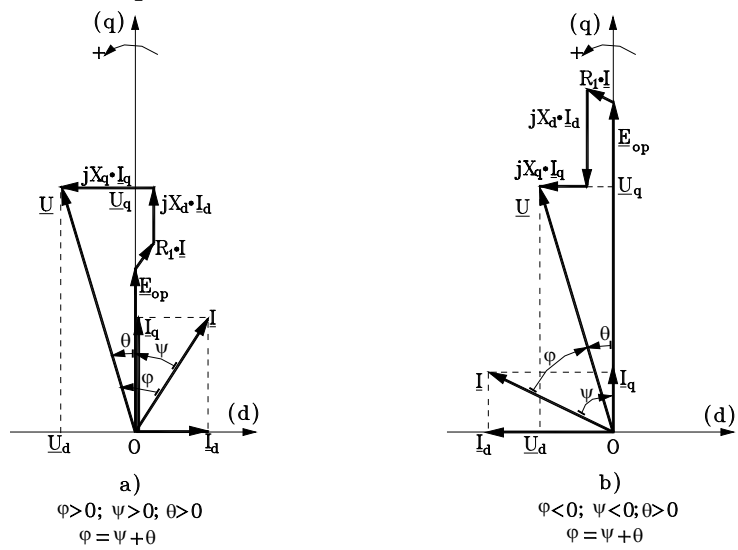

Figure 7. Blondel phasor diagram of synchronous motor with salient poles; a) under-excited operation (inductive current I); b) over-excited operation (capacitive current $\underline{\text { I}}$ )

In these conditions, the electromagnetic torque of the synchronous motor with salient poles $\mathrm{M}_{\mathrm{I}}$ (at the current supplying) is determined as follows [1,9]:

$M_{I}=\frac{3 \cdot p}{\omega}\left[E_{0 p} \cdot I \cdot \cos \Psi+\left(X_{d}-X_{q}\right) I^{2} \cdot \sin \Psi \cdot \cos \Psi\right]$

which can be put in the final form [1]:

$$
M_{I}=\frac{3 \cdot p}{\omega} \cdot\left[E_{0 p} \cdot I \cdot \cos \Psi+\frac{1}{2} I^{2}\left(X_{d}-X_{q}\right) \cdot \sin 2 \Psi\right]
$$

On the whole, the presence of two components $\mathrm{M}_{\mathrm{I}}=\mathrm{M}_{\mathrm{I}}{ }^{\prime}$ $+\mathrm{M}_{\mathrm{I}}$ " is noticed.

The main component:

$$
M_{I}^{\prime}=\frac{3 \cdot p}{\omega} E_{0 p} \cdot I \cdot \cos \Psi
$$

depends on the excitation degree (namely, the magnitude of excitation current $\mathrm{I}_{\mathrm{e}}$ ), while the secondary component:

$$
M_{I}^{\prime \prime}=\frac{3 \cdot p}{\omega} \cdot \frac{I^{2}}{2} \cdot\left(X_{d}-X_{q}\right) \cdot \sin 2 \Psi
$$

is determined by the magnetic asymmetry of the rotor, being present (non-zero) even in the absence of the synchronous motor excitation. At $\mathrm{I}=\mathrm{ct}$., $\mathrm{f}=\mathrm{ct}$. and excitation current $\mathrm{I}_{\mathrm{e}}=$ ct. (when $\mathrm{E}_{0 \mathrm{p}}=$ ct.), the electromagnetic torque $\mathrm{M}_{\mathrm{l}}$ depends solely on the load angle $\psi$.

For the salient pole synchronous motor, the characteristic $M_{I}=f(\psi)$ is represented in Figure 8 by a thick line.

In the case of non-salient pole motors, in which $X_{d}=X_{q}=X_{s}$ the secondary component will not appear and the load characteristic $M_{I}=f(\psi)$ is represented just by the main component with a cosine variation. 


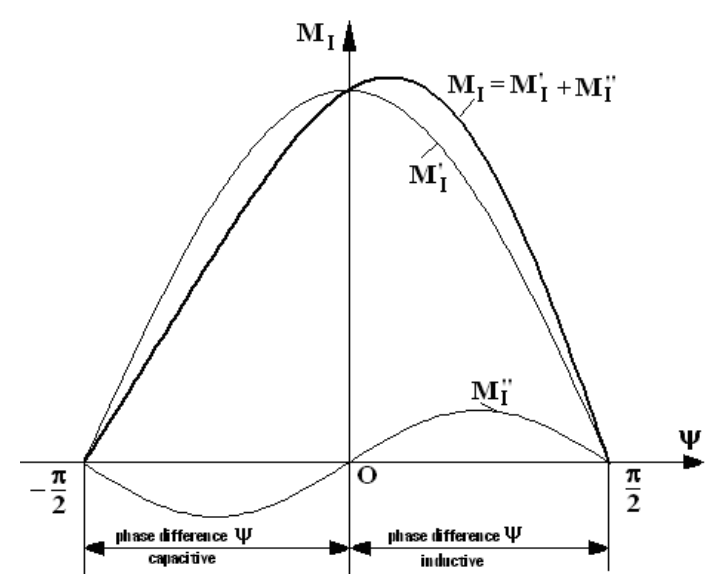

Figure 8. Characteristic representation $\mathrm{M}_{\mathrm{I}}=\mathrm{f}(\psi)$ of synchronous motor with salient poles at powering from a three-phase source of sinusoidal currents

Note that if in formula (31) of the torque $M_{I}$ we make the following substitutions:

$E_{0 p}=\omega \cdot\left(w_{1} \cdot k_{w 1} \frac{\Phi_{o m}}{\sqrt{2}}\right) ; \quad X_{d}=\omega \cdot L_{d}$ and $X_{q}=\omega \cdot L_{q}$

then the electromagnetic torque expression $M_{I}$ (at the supply current) becomes:

$M_{I}=3 p \cdot\left(w_{1} \cdot k_{w 1} \frac{\Phi_{o m}}{\sqrt{2}}\right) \cdot I \cos \Psi+\frac{3 p}{2} \cdot I^{2}\left(L_{d}-L_{q}\right) \cdot \sin 2 \Psi$

In relations (32) and (33) the physical significance of the new quantities follows:

$\mathrm{w}_{1}=$ the number of turns, in series, on a stator phase of synchronous motor;

$\mathrm{k}_{\mathrm{w} 1}=$ the winding factor of a stator phase;

$\Phi_{\mathrm{om}}=$ the maximum value of the main magnetic flux, depending on the magnitude of excitation current $\mathrm{I}_{\mathrm{e}}$, namely $\Phi_{\text {om }}=\mathrm{f}\left(\mathrm{I}_{\mathrm{e}}\right)$;

$\mathrm{L}_{\mathrm{d}}=$ the longitudinal inductance of stator winding;

$\mathrm{L}_{\mathrm{q}}=$ the transverse inductance of stator winding of synchronous motor.

Particularly, for $\psi=0$ (when $\mathrm{I}_{\mathrm{d}}=0$ and $\mathrm{I}_{\mathrm{q}}=\mathrm{I}$ ), the expression (33) of the electromagnetic torque $\mathrm{M}_{\mathrm{I}}$ becomes:

$$
M_{I}=M_{I}^{\prime}=3 p\left(w_{1} \cdot k_{w 1} \frac{\Phi_{o m}}{\sqrt{2}}\right) \cdot I=K \cdot \Phi_{o m} \cdot I
$$

so that $\mathrm{M}_{\mathrm{I}}$ takes on a form that is mathematically identical to the electromagnetic torque $\mathrm{M}=\mathrm{C}_{\mathrm{m}} \cdot \Phi \cdot \mathrm{I}$ developed by a DC motor (with collector) with separated excitation. In relation (34), with $\mathrm{K}$ has been denoted the constructive constant $K=3 p \cdot w_{1} \cdot k_{w 1} \frac{1}{\sqrt{2}}$ of the synchronous motor.

Expression (33) highlights that at $\mathrm{I}_{\mathrm{e}}=$ ct., $\mathrm{I}=$ ct. and $\psi=$ ct. the electromagnetic torque $\mathrm{M}_{\mathrm{I}}$ is constant (and nonzero) and has the same magnitude regardless of the numerical value of the frequency f of the stator currents.

The existence of nonzero electromagnetic torque at the powering in current (by magnitude I phase shift $\psi=$ ct. related to the counter-electromotive forces $\mathrm{E}_{\mathrm{op}}$ ) leads to the development of synchronous motor applications in electric traction.

On electric locomotives, the traction synchronous motor is powered from a current inverter (thyristorised), with natural commutation, determined exactly by the counter- electromotive forces $\mathrm{E}_{\mathrm{op}}$ (induced in the stator windings of the synchronous motor).

In order to ensure the phase shift $\psi$ (of the current fundamental I leading the counter-electromotive forces $\mathrm{E}_{\mathrm{op}}$ ), the control of the thyristors' conduction is based on the signals from a position transducer solidary with the rotor.

\subsection{Diagram of currents for the traction synchronous motor}

The synchronous motor will be over-excited and the threephase induced counter-electromotive forces $\left(-\mathrm{e}_{0 \mathrm{~A}},-\mathrm{e}_{0 \mathrm{~B}},-\mathrm{e}_{0 \mathrm{C}}\right)$ of frequency $\mathrm{f}=\omega / 2 \pi$ are able to drive the commutation of the current inverter thyristors at any speed $\Omega>\Omega_{\min }$ without risk of losing synchronism between rotor and rotating magnetic field [1,4-6,9].

Specifically, at any speed " $n$ " of the rotor of self-piloted synchronous motor (corresponding to the frequency $\mathrm{f}=\mathrm{p} \cdot \mathrm{n} / 60$ of stator currents) through the induced counterelectromotive forces the synchronous motor is piloting the converter which, from the DC current $\mathrm{I}_{0}$, is distributing (on each of the three phases of the stator) current pulses of amplitude $\pm \mathrm{I}_{0}$, duration $\mathrm{T} / 3$ and a repetition frequency $\mathrm{f}=1 / \mathrm{T}=\omega / 2 \pi$ which is proportional to the angular mechanical speed of rotor rotation $\Omega=\omega / p$ (see Fig. 9).

The angular mechanical speed $\Omega$ of rotor results from the fundamental equation of motion:

$$
J \cdot \frac{d \Omega}{d t}=M-M_{e x}
$$

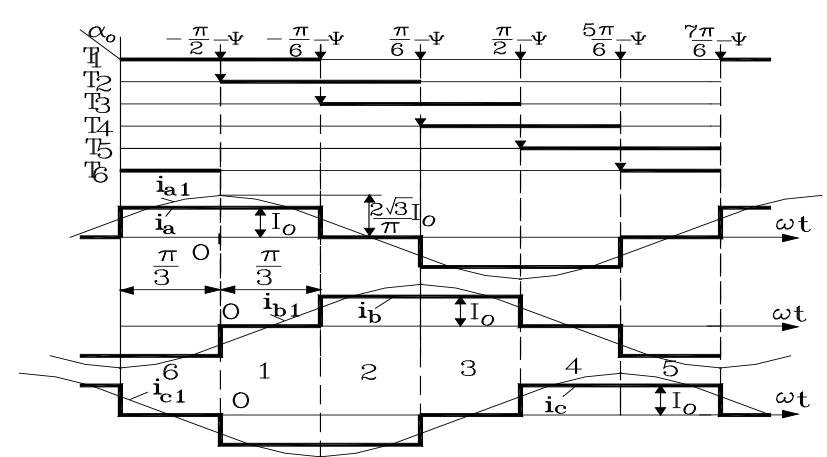

Figure 9. Conduction intervals of three-phase thyristor bridge and shapes of variation with time of currents $i_{a}, i_{b}$, şi, $i_{c}$ (and their fundamentals $i_{a 1}, i_{b 1}, s_{i}, i_{c 1}$ )

Under the simplifying assumption of a DC current $\mathrm{I}_{0}$ that is perfectly smooth (when $\mathrm{L}_{0} \rightarrow \infty$ ) and neglecting the commutation durations, the stator currents $i_{a}, i_{b}$, şi, $i_{c}$ (flowing through the phases of synchronous motor) will take on the forms of variation with time depicted in Figure 9.

In these conditions the fundamentals of stator currents (denoted by $i_{a 1}, i_{b 1}$, si, $i_{c 1}$ in Figure 9) form a three-phase symmetrical current system (by direct sequence) with frequency $\mathrm{f}=\omega / 2 \pi$ and the effective $\mathrm{I}_{1}$ value given by:

$$
I_{1}=\frac{\sqrt{6}}{\pi} \cdot I_{0}
$$

\subsection{Synchronization of commands}


Operation of the self-piloted synchronous motor is based on ensuring the capacitive shift phase $\psi=$ ct. between the space phasor of stator currents and the axis q. This condition is verified six times during each time period $\mathrm{T}$ (by controlling the moments of thyristor ignition relative to the position $\alpha=\omega t+\alpha_{0}$ of the axis $d$ of the rotor). For this purpose, a position transducer TP provides the rotor positions (with respect to a reference direction of the stator) at which the bridge thyristors of the current inverter IC are on [1,4-6,9].

Ideally, for harmonic variation of stator currents, their space phasor $\underline{\mathrm{i}}_{1 \mathrm{dq}}$ (in the rotor referential $(\mathrm{d}, \mathrm{q})$ ) is a fixed phasor, mathematically expressed by:

$$
\begin{aligned}
& \underline{i}_{I d q}=\sqrt{2} I_{1} \cdot e^{j\left(\frac{\pi}{2}+\psi\right)} \\
& \text { with } I_{1}=\frac{\sqrt{6}}{\pi} \cdot I_{0}
\end{aligned}
$$

In the fixed stator referential the space phasor $\underline{i}_{1 d q}$ matches the expression $\underline{i}_{1 \mathrm{~s}}$ :

$\underline{i}_{l s}=\frac{2}{3}\left(i_{a l}+a i_{b l}+a^{2} i_{c l}\right)=\underline{i}_{l d q} e^{j \alpha}=\frac{2 \sqrt{3}}{\pi} I_{0} \cdot e^{j\left(\frac{\pi}{2}+\psi+\alpha\right)}$

with $\alpha=\omega t+\alpha_{0}$.

If the reference stator axis overlaps the magnetic axis of phase $\mathrm{A}$, and the temporal origin $(\omega \mathrm{t}=0)$ is chosen when the current $i_{a 1}$ (phase $A$ ) passes through a maximum (a moment that is coinciding with thyristor ignition timing), the space phasor $\underline{i}_{1 \mathrm{~s}}$ will be of the form:

$$
\underline{i}_{1 s}=\sqrt{2} \cdot I_{1} \cdot e^{j \omega t}=\sqrt{2} \cdot\left(\frac{\sqrt{6}}{\pi} I_{0}\right) \cdot e^{j \omega t}
$$

From the expressions (38) and (39), it follows that:

$$
\frac{\pi}{2}+\psi+\alpha_{0}=0 \Rightarrow \alpha_{0}=-\left(\frac{\pi}{2}+\psi\right)
$$

This angle represents the rotor position at the moment of ignition of thyristor $T_{2}$. The other thyristors will be switched on their natural succession (at successive positions of the rotor evenly shifted by $\pi / 3$ electric radians) as in Figure 9.

\subsection{Considering the sinusoidal currents}

When considering only the fundamentals of stator current, the space phasor $\underline{i}_{1 d q}$ (in the rotating referential $d, q$ ) is fixed and is subject to the expression (in polar form) given by (37). From this relationship, identifying the equivalent algebraic form:

$$
\underline{i}_{1 d q}=\sqrt{2} \cdot I_{1} \cdot e^{j\left(\frac{\pi}{2}+\psi\right)}=\sqrt{2} \cdot\left(I_{1 d}+j \cdot I_{1 q}\right)
$$

where the effective values $I_{1 d}$ and $I_{1 q}$ of the orthogonal components are:

$$
\begin{aligned}
& I_{1 d}=-I_{1} \cdot \sin \psi=-\left(\frac{\sqrt{6}}{\pi} I_{0}\right) \sin \psi \\
& I_{1 q}=I_{1} \cdot \cos \psi=\left(\frac{\sqrt{6}}{\pi} I_{0}\right) \cos \psi
\end{aligned}
$$

If further in the expression of the electromagnetic torque $M$ the following substitutions are performed: $\mathrm{I}_{\mathrm{d}}=\mathrm{I}_{1 \mathrm{~d}}$ and $\mathrm{I}_{\mathrm{q}}=\mathrm{I}_{1 \mathrm{q}}$, the following result holds for $\mathrm{M}=\mathrm{M}_{\mathrm{I}}$ :

$M_{I}=3 p \cdot\left[\frac{\sqrt{6}}{\pi} \cdot I_{0} \cdot\left(K \Phi_{0 m}\right) \cdot \cos \psi-\frac{3}{\pi^{2}} \cdot I_{0}^{2} \cdot\left(L_{d}-L_{q}\right) \cdot \sin 2 \psi\right]$

where the average value of current $\mathrm{I}_{0}$ (which is established in the DC intermediary circuit) is calculated from the relationship:

$$
I_{0}=\frac{U_{1 d}-V_{d \alpha}}{R_{0}}
$$

The sole problem of self-piloted synchronous motor is the starting regime [1,4-6,9]. At low rotational speeds, under $5 \%$ of $\Omega_{\max }$, the counter-electromotive force $\left(-\mathrm{e}_{0 \mathrm{p}}\right)$ becomes unable to ensure the commutation of the thyristors of the current inverter (CI). In this speed range, assisted commutation is applied, usually realized by the device AC through creative options.

\subsection{Considering the non-sinusoidal currents}

In very deed, the phase currents $i_{a}, i_{b}, i_{c}$ are strongly distorted as against the ideal sinusoidal shape [1,9]. Actually, under the simplifying assumptions adopted, each phase current $\left(i_{a}, i_{b}\right.$ or $i_{c}$ from Fig. 9) consists of "rectangular blocks" of amplitude $\pm \mathrm{I}_{0}$ (and duration equal to $2 \pi / 3$ ) separated by intervals (by duration $\pi / 3$ ) in which the currents are null.

Moreover, the fundamentals of phase currents (denoted by $i_{a 1}, i_{b 1}$ and $i_{c 1}$ in Figure 9) have equal amplitudes (of magnitude $\frac{2 \sqrt{3}}{\pi} \mathrm{I}_{0}$ ) and they are shifted, one lagging another, with the same angle of $2 \pi / 3$, forming a symmetrical three-phase system of sinusoidal currents, by direct succession. One could notice that by $\mathrm{I}_{0}$ is denoted the DC intensity from the DC intermediary circuit.

In the fixed stator referential $\alpha \beta$, with the real axis $\mathrm{O} \alpha$ overlapped to reference stator winding axis A and with the temporal origin $(\omega \mathrm{t}=0)$ chosen at the moment when its current is passing through a maximum (when $i_{a 1}=\frac{2 \sqrt{3}}{\pi} I_{0}$ ), the space phasor $\underline{i}_{1 s}$ of stator current fundamentals, calculated with the formula:

$$
\underline{i}_{1 s}(\omega t)=\frac{2}{3} \cdot\left(i_{a 1}+a \cdot i_{b 1}+a^{2} \cdot i_{c 1}\right)=\sqrt{2}\left(\frac{\sqrt{6}}{\pi}\right) I_{0} \cdot e^{j \omega t}
$$

is a rotating phasor (with the angular speed $\omega=\mathrm{ct}$ ) with the top-point describing the circle of radius equal to $\sqrt{2}\left(\frac{\sqrt{6}}{\pi}\right) \cdot \mathrm{I}_{0}=\frac{2 \cdot \sqrt{3}}{\pi} \cdot \mathrm{I}_{0}$ (represented by dashed line in Figure 10) 
In the same time interval, still in the fixed stator referential $\alpha \beta$, the space phasor $\underline{i}_{s}$ (of non-sinusoidal currents) is completely different. For this reason, analytically it will proceed to an evaluation of this space phasor on each angular interval (by width $\pi / 3$ ), in which the stator currents $i_{a}, i_{b}$ and $i_{c}$ remain constant. Thereby:

1. In the first interval $0 \leq \omega t \leq \pi / 3$ when $i_{a}=+I_{0}, i_{b}=0$ and $\mathrm{i}_{\mathrm{c}}=-\mathrm{I}_{0}$ the space phasor $\underline{\mathrm{i}}_{\mathrm{s}}$ is fixed (position " 0 " in Figure 10) and has the expression:

$\underline{i}_{-s}(\omega t)=\frac{2}{3}\left(i_{a}+a \cdot i_{b}+a^{2} \cdot i_{c}\right)=\frac{2}{3} \cdot\left(I_{0}-a^{2} \cdot I_{0}\right)=\frac{2}{\sqrt{3}} \cdot I_{0} \cdot e^{j \frac{\pi}{6}} ; \quad 0 \leq \omega t<\frac{\pi}{3}$

2. In the interval $(\mathrm{k}+1)$ by width $\pi / 3$, when $\omega$ t may be written as:

$$
\omega t=k \cdot \frac{\pi}{3}+\omega t^{\prime} ; \quad 0 \leq \omega t^{\prime}<\frac{\pi}{3} ; \quad k=1,2,3 \ldots
$$

the space phasor $\underline{i}_{s}$ remains fixed (in position " $k$ ", $\mathrm{k}=1,2,3 \ldots$ in Figure 10) on whole duration $0 \leq \omega \mathrm{t}^{\prime}<\pi / 3$.

Broadly speaking, for any $\omega t$ by type (46), the expression of space phasor $\underline{i}_{\mathrm{s}}$ can be written as:

$$
\underline{i}_{s}(\omega t)=\frac{2}{\sqrt{3}} \cdot I_{0} \cdot e^{j\left(\frac{\pi}{6}+k \cdot \frac{\pi}{3}\right)}
$$

with $k=0,1,2,3 \ldots$

During each period $\omega T=2 \pi$, the space phasor $\dot{i}_{s}(\omega t)$ of non-sinusoidal currents will successively scan all 6 fixed positions (denoted by "0", "1", “2”, “3", “4”, "5" in Figure 10). At each position it will remain motionless for

$$
\mathrm{t}^{\prime}=\frac{\pi}{3 \omega}=\frac{\pi}{3}\left[\frac{\mathrm{T}}{2 \pi}\right]=\frac{\mathrm{T}}{6},
$$

that time being numerically equal to the duration between two successive commutations of the bridge, then instantly "jumps" to the next position.

Geometrically, over the duration of each period $\omega \mathrm{T}=2 \pi$, the "jumping" space phasor $\underline{i}_{s}(\omega t)$ performs a complete rotation, like the rotating phasor $\underline{i}_{1 s}(\omega t)$ of current fundamentals $[1,9]$. Accordingly, the virtual angular speed $\omega_{\text {vir }}$ (fictitious average) of rotation of "jumping" phasor of non-sinusoidal currents $\omega_{\text {vir }}=\frac{2 \pi}{\mathrm{T}}=2 \pi \mathrm{f}=\omega$ is numerically equal to the rotation angular speed $\omega$ of the rotating phasor of stator current fundamentals. Consequently, this common value $\omega$ of angular speeds will be used at changing the referential of space phasors.

In the coordinates $(\mathrm{d}, \mathrm{q})$ rotating with angular speed $\omega$, the space phasor $\underline{\underline{i}}_{1 \mathrm{~s}}$ will become $\underline{\underline{i}}_{1 \mathrm{dq}}$, while the space phasor $\underline{\underline{i}}_{\mathrm{s}}$ will become $\bar{i}_{\mathrm{dq}}$. At changing the referential, the relations among these phasors are as the form:

$$
\begin{aligned}
& \underline{i}_{1 d q}=\underline{i}_{1 s} \cdot e^{-j \alpha} ; \quad \alpha=\alpha_{0}+\omega t \\
& \underline{i}_{d q}=\underline{i}_{s} \cdot e^{-j \alpha} ; \quad \alpha=\alpha_{0}+\omega t
\end{aligned}
$$

With expression (44) for $\underline{\underline{i}}_{1 \mathrm{~s}}$, the relation of phasor $\underline{\underline{i}}_{1 \mathrm{dq}}$ given by (48) takes on the form:

$$
\underline{i}_{I d q}=\sqrt{2} \cdot\left(\frac{\sqrt{6}}{\pi}\right) \cdot I_{0} \cdot e^{j \omega t} \cdot e^{-j\left(\alpha_{0}+\omega t\right)}=\frac{2 \sqrt{3}}{\pi} I_{0} \cdot e^{-j \alpha_{0}}
$$

Similarly, for any $\omega t$ of the form: $\omega t=k \cdot \frac{\pi}{3}+\omega t^{\prime}$

with $0 \leq \omega t^{\prime}<\frac{\pi}{3}$.

and $\mathrm{k}=0,1,2,3, \ldots$ when, in fixed coordinates, the space phasor $\underline{i}_{s}$ has the expression (47), it will result that, in synchronous rotating coordinates, the space phasor $\underline{\underline{i}}_{\mathrm{dq}}$ will be established by:

$i_{d q}=\frac{2}{\sqrt{3}} \cdot I_{0} \cdot e^{j\left(\frac{\pi}{6}+k \frac{\pi}{3}\right)} \cdot e^{-j\left(\alpha_{0}+k \cdot \frac{\pi}{3}+\omega t^{\prime}\right)}=\frac{2}{\sqrt{3}} \cdot I_{0} \cdot e^{j\left(\frac{\pi}{6}-\alpha_{0}-\omega t^{\prime}\right)}$

If the initial position $\alpha_{0}$ it is chosen accordingly to relation (40), meaning $\alpha_{0}=-\left(\frac{\pi}{2}+\psi\right)$, then in rotating coordinates $(\mathrm{d}, \mathrm{q})$, the space phasors $\underline{\underline{i}}_{1 \mathrm{dq}}$ and $\underline{\mathrm{i}}_{\mathrm{dq}}$ become respectively:

$$
\underline{i}_{l d q}=\frac{2 \sqrt{3}}{\pi} \cdot I_{0} \cdot e^{j\left(\frac{\pi}{2}+\psi\right)}=j \cdot \frac{2 \sqrt{3}}{\pi} \cdot I_{0} \cdot e^{j \psi}
$$

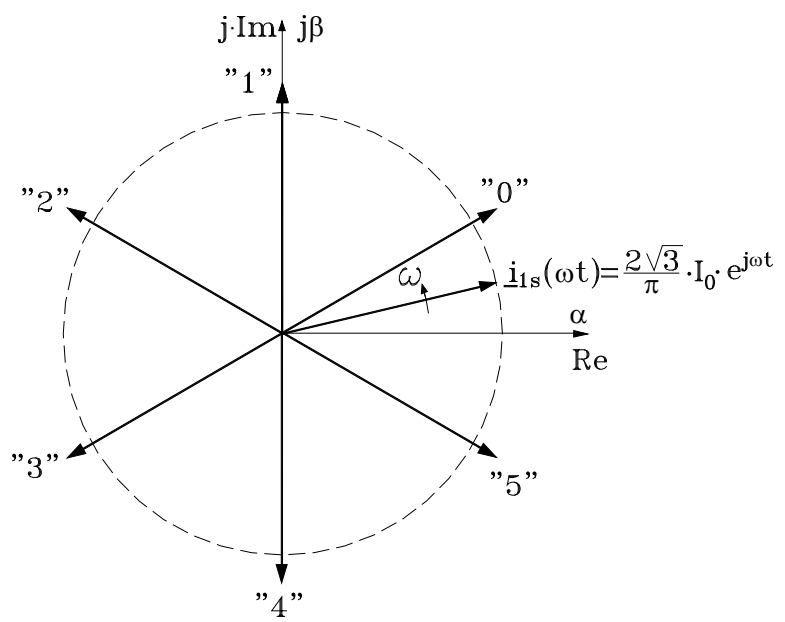

Figure 10. Rotating space phasor $\underline{i}_{1 s}(\omega t)$ and the 6 fixed positions of non-sinusoidal current phasor $\underline{i}_{s}(\omega t)$ in the fixed stator referential

$$
\underline{i}_{d q}=\frac{2}{\sqrt{3}} \cdot I_{0} \cdot e^{j\left(\frac{\pi}{2}+\psi+\frac{\pi}{6}-\omega t^{\prime}\right)}=j \cdot \frac{2}{\sqrt{3}} \cdot I_{0} \cdot e^{j\left(\psi+\frac{\pi}{6}-\omega t^{\prime}\right)}
$$

Space phasors $\underline{i}_{1 \mathrm{dq}}$ and $\underline{\mathrm{i}}_{\mathrm{dq}}$ are geometrically represented in Figure 11, in the interval $0 \leq \omega t^{\prime}<\frac{\pi}{3}$ (on the time duration $0 \leq t<\frac{\pi}{3 \omega}=\frac{\pi \cdot T}{3 \cdot 2 \pi}=\frac{T}{6}$ ), meaning that exactly the duration $\mathrm{T} / 6$ between two successive commutations of the bridge.

Figure 11 emphasizes that during the time between two successive commutations $\mathrm{T} / 6$ the space phasor $\underline{\mathrm{i}}_{\mathrm{dq}}$ rotates in opposite sense, with the angular speed $\omega=$ ct., its extremity describing the arc between the points 1 and 2 corresponding to an angle at the centre of $\pi / 3$ electrical radians $[1,9]$. 
At the moment $\mathrm{t}^{\prime}=0$, the phasor $\underline{\mathrm{i}}_{\mathrm{dq}}$ starts from initial position 1 (corresponding to angle $\psi+30^{\circ}$ ) towards the final position 2 (corresponding to angle $\psi-30^{\circ}$ ), reached after $\mathrm{t}^{\prime}=\mathrm{T} / 6$. At each commutation of the bridge, the space phasor $\underline{i}_{d q}$ instantly returns from position 2 to position 1 , then the oscillation around the fixed phasor $\underline{i}_{1 \mathrm{dq}}$ is repeated in an identical manner.

Accordingly, the electromagnetic torque $\mathrm{M}_{\mathrm{I}}$ developed by the self-piloted synchronous motor will oscillate.

In order to evaluate the electromagnetic torque $M_{I}$, we first establish the effective values $I_{d}\left(t^{\prime}\right)$ and $I_{q}\left(t^{\prime}\right)$ of the orthogonal components of phasor $\underline{i}_{\mathrm{dq}}$ :

$$
\underline{i}_{d q}=\sqrt{2} \cdot\left[I_{d}\left(t^{\prime}\right)+j \cdot I_{q}\left(t^{\prime}\right)\right]=j \cdot \frac{2}{\sqrt{3}} \cdot I_{0} \cdot e^{j\left(\psi+\frac{\pi}{6}-\omega t^{\prime}\right)}
$$

Then, by identifying terms, the following immediately is observed:

$$
\begin{aligned}
& I_{d}\left(t^{\prime}\right)=-\sqrt{\frac{2}{3}} I_{0} \sin \left(\psi+\frac{\pi}{6}-\omega t^{\prime}\right) \\
& I_{q}\left(t^{\prime}\right)=\sqrt{\frac{2}{3}} I_{0} \cos \left(\psi+\frac{\pi}{6}-\omega t^{\prime}\right)
\end{aligned}
$$

If in expression (30) of the electromagnetic torque $\mathrm{M}$ there are performed the substitutions $\mathrm{I}_{\mathrm{d}}=\mathrm{I}_{\mathrm{d}}\left(\mathrm{t}^{\prime}\right)$ and $\mathrm{I}_{\mathrm{q}}=\mathrm{I}_{\mathrm{q}}\left(\mathrm{t}^{\prime}\right)$ specified by (45), then the torque $\mathrm{M}_{\mathrm{I}}$ takes on the form:

$$
M_{I}\left(t^{\prime}\right)=3 p \cdot\left[\left(K \Phi_{0 m}\right) \cdot \sqrt{\frac{2}{3}} I_{0} \cos \left(\psi+\frac{\pi}{6}-\omega t^{\prime}\right)-\frac{I_{0}^{2}}{3}\left(L_{d}-L_{q}\right) \sin 2\left(\psi+\frac{\pi}{6}-\omega t^{\prime}\right)\right]
$$

This expression of the torque is valid in each interval $0<$ $\omega \mathrm{t}^{\prime}<\pi / 3$ between two successive commutations of the bridge. Overall, the torque $\mathrm{M}_{\mathrm{I}}$ is irregular.

The non-uniformity of electromagnetic torque $M_{I}$ is caused by the variation of the orthogonal components $I_{d}\left(t^{\prime}\right)$ and $I_{q}\left(t^{\prime}\right)$, according to (31), this variation being determined by the oscillation of space phasor $\underline{i}_{d q}$ around the fixed phasor $\underline{i}_{1 \mathrm{dq}}$. On each period $\mathrm{T}$ (of non-sinusoidal variation of currents) the electromagnetic torque $M_{I}$ performs six pulsations of the type described by relationship (56).

In order to attenuate pulsations of electromagnetic torque one is searching for ways to limit the oscillation amplitude of phasor $\underline{\mathrm{i}}_{\mathrm{dq}}$ (for instance between $\psi+15^{\circ}$ and $\psi-15^{\circ}$ ). For this goal, the stator winding of synchronous motor is divided in two distinct three-phase windings (spatially shifted with $\pi / 6$ electrical radians), each being separately supplied from a current inverter. If the two inverters provide current pulses shifted from each other by $\pi / 6$ electric radians, then it could be achieved a system with the pulsation index $\mathrm{q}=2 \cdot 6=12$, consequently with a pulsation period of the electromagnetic torque equal to $T / 12$. It follows implicitly that the amplitude of torque pulsation will be less.

\section{Conclusions}

Addressing the sustainability of operation of the AC traction electric motors constitutes a challenge in electric railway transportation research.

An electromagnetic torque capability analysis of the traction AC electric motors has been carried out in this study.

The analysis of the torque capability of the traction inductor motor emphasizes that the greatest magnitudes of electromagnetic torque are obtained for operation at a constant stator flux $\Psi_{\mathrm{s}}=$ ct. The study highlights that the

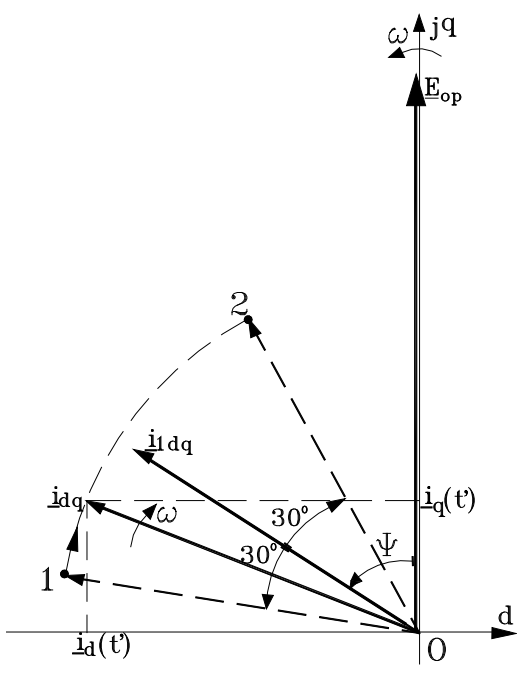

Figure 11. Oscillations of phasor $\underline{i}_{\mathrm{dq}}$ around $\underline{i}_{1 \mathrm{dq}}$ in case of rectangular currents

maximum electromagnetic torque when the induction motor is operating at constant useful flux $\Psi_{\mathrm{u}}=$ ct. is approximately $20 \%$ smaller than the maximum torque when operating at $\Psi_{\mathrm{s}}=$ ct. Moreover, at the imposed electromagnetic torque, the smallest value of rotor pulsation is obtained for operation with $\Psi_{\mathrm{s}}=$ ct. The analysis of induction machine operation with constant flux highlights also that only at constant rotor flux $\Psi_{r}^{\prime}=$ ct. do the induction machine mechanical characteristics not have extremum points; rather they are straight lines. These linear characteristics are preferable for the applications which demand high sustainability dynamics in induction machine operation.

The study of traction synchronous motor emphasizes that electric traction drive systems using synchronous motors fed by current inverters provide high performance for high speed electric trains, in terms of both train dynamics and sustainability. With respect to the electromagnetic torque capability of the traction synchronous motor, the paper highlights that in order to synchronize the machine rotating field with the rotor (and avoiding the risk of losing the synchronism at any frequency value of stator currents) the synchronous motor will control the current inverter which is powering it, becoming in this way a self-piloted synchronous motor. Actually, the position of direct axis of synchronous motor rotor will be checked in an evolutionary sense in time (through position transducers) $6 \cdot \mathrm{p}$ times during each complete rotation (at any value of rotor speed), by the ignition control of the thyristor of the current inverter bridge that is supplying the motor. Hence, the paper emphasizes that at electrically driven railway systems with traction synchronous motors the functions of amplitude adjustment are completely separate from those of the frequency control. As a consequence, the result is a simpler construction for both the power part and the 
control electronics of static converters.

The paper supports the findings that electric traction drive systems using three-phase induction and synchronous motors fed by variable voltage or current variable frequency inverters enhance the sustainable operation of electric railway trains. The results of this work may lead to enhancements of the main criteria for optimising the safe and efficient operation of railway electric traction systems.

\section{References}

1. D.A. Nicola, Tractiune electrica (Electric Traction), Universitaria Publishing House, Craiova, Romania (2012).

2. M.A. Rosen, D.A. Nicola, C.A. Bulucea, D.C. Cismaru, Sustainability, 7, 3441-3459 (2015).

3. C.A. Bulucea, D.A. Nicola, N.E. Mastorakis, M.A. Rosen, Recent Researches in Energy and Environment: Proc. 6th IASME/WSEAS Int. Conf. on Energy and Environment, Cambridge, UK, February 20-25, pp. 182-191 (2011).

4. R. Kaller, J.M. Allenbach, Traction Electrique (Electrical Traction), Vol. 1-2, PPUR, Lausanne, (1995).

5. F. Perticaroli, Sistemi elettrici per $i$ transporti: Trazione elettrica (Electrical Systems for Transportation: Electric Traction). Ed. Masson, Milano-Parigi-Barcellona (1994).

6. J.A. Lozano, J.Félez, J.de Dios Sanz, J. M. Mera, Railway Traction, Reliability and Safety in Railway, Dr. Xavier Perpinya (Ed.), (2012), Available at: http://www.intechopen.com/books/reliability-andsafety-in-railway/railway-traction, Accessed on 15 February 2016.

7. T. Koseki, The 2010 International Power Electronics Conference, pp. 2836-2741 (2010), Available at: http://koseki.t.u-tokyo.ac.jp/report2010/141-146.pdf, Accessed on 10 February 2016

8. M. Georgescu, Tracţiunea electrică de mare viteză cu motoare sincrone (High Speed Electric Traction with Synchronous Motors), Dacia Publishing House, Cluj-Napoca (2001).

9. C.A. Bulucea D.A. Nicola, D.C. Cismaru, N.E. Mastorakis, C.A. Bulucea, C. Brindusa, Advances in Environmental Sciences, Development and Chemistry, Proc. 2014 Int. Conf. on Energy, Environment, Development and Economics (EEDS 2014), Santorini Island, Greece, July 17-21, pp. 2128 (2014).

10. D.A. Nicola, M.A. Rosen, C.A. Bulucea, C. Brandusa, Proc. $6^{\text {th }}$ WSEAS Int. Conf. on Engineering Education (EE'09), Rhodes, Greece, July 22-24, pp. 124-132 (2009).

11. M.A. Rosen, Proc. $3^{\text {rd }}$ IASME/WSEAS Int. Conf. on Energy \& Environment, Cambridge, UK, Feb. 23-25, 136-142 (2008).

12. I. Dincer, M.A. Rosen, Exergy: Energy, Environment and Sustainable Development, 2d ed., Elsevier: Oxford, UK (2013).
13. C.A. Bulucea, D.A. Nicola, M.A. Rosen, N.E. Mastorakis, C.A. Bulucea, Recent Advances in Environmental and Earth Sciences and Economics, Proc. 2015 Int. Conf. on Energy, Environment, Development and Economics (EEDE 2015), Zakynthos Island, Greece, July 16-20, pp. 108-115 (2015).

14. J. Chatelain, Machines électriques (Electrical Machines), PPUR, Lausanne (1989).

15. D.A. Nicola, C.A. Bulucea, Electrotechnics, Electrical Equipment and Machines, Vol. II "Electrical Equipment", SITECH Publishing House, Craiova (2005) 